\title{
Changes in the Portfolio Management and Construction under the Pandemic Era
}

\author{
Ruipeng Tan ${ }^{1, \square}$ \\ ${ }^{1}$ School of Liberal Arts, University of Massachusetts Boston, Dorchester, MA 02125, The United States;
}

\begin{abstract}
This paper focuses on comparing portfolio management and construction before and after the coronavirus. First, this paper presents the importance of building up portfolios for investors to diversify their risks. Theories on portfolio management are discussed in this section to show how they have been developed to help on investing and reduce risk. Then, the paper moves on to show the impact of the pandemic on the financial market and portfolio management. Sample data on tech stock returns are collected to perform a Monte Carlo simulation on portfolio construction to find out the efficient portfolio before and after the COVID-19 outbreak. The efficient portfolio is build based on the Markowitz theory to find the combination. Comparisons between these portfolio constructions are made to find out the changes in portfolio management and construction under the pandemic era. In conclusion, this paper presents how pandemic has changed and impacted the investments and lists recommendations on future portfolio management and construction.
\end{abstract}

\section{INTRODUCTION}

Portfolio construction is the common way for investors to reduce the risk by applying diversified portfolios across different asset classes and strategies. Portfolio construction is the selection of securities for inclusion in a portfolio and the determination of their appropriate weights of each security in that portfolio. The Markowitz model suggests that a reasonable goal for portfolio construction should be to form a portfolio with the highest return for a given level of risk. A portfolio with such characteristics is called an efficient portfolio, and it has been widely accepted as a classic model for optimal portfolio construction.

Global capital markets have seen significant declines due to the impact of the pandemic outbreak. According to the Centers for Disease Control and Prevention, there are over 26 million confirmed cases in the U.S. by the end of January 2021 [1]. Major national markets around the world experienced significant declines due to the continued spread of the epidemic and major stock valuations in Europe and the U.S. plummeted with the crude oil once fell below normal levels. The market fears that the COVID-19 will cause companies to miss capacity, revenue, and earnings expectations in the next few years, dragging down macro data in various countries. The Federal Reserve cut interest rates to a record low of $0-0.25 \%$ in March 2020 in succession to ease the liquidity pressure that continues to be transmitted between different capital markets $[2,3]$. Under this global financial turmoil, many portfolios have been taking great hits from COVID-19, and it is meaningful to find out what changes the pandemic has brought to the portfolio construction and any shifts in the investments.

\section{LITERATURE REVIEW}

Portfolio construction is one of the critical issues for practitioners and academicians in the quantitative finance field. It is a disciplined, personalized process. In constructing a portfolio, the individual risk and return characteristics of the underlying investments must be considered along with your unique needs, goals, and risk considerations. The evolution of portfolio construction began in 1952 when Harry Markowitz published a thesis named Portfolio Selection. Numbers of empirical studies regarding portfolio construction occurred years later. Sharpe in 1964 afterward expanded on Markowitz's theory with the Capital Asset Pricing Model, which introduced alpha, the excess return of the asset relative to the return of the benchmark index, and beta, the risk of the asset relative to the market [4].

One of Markowitz's innovations was to introduce risk into the capital theory model and to use mathematical and statistical tools to demonstrate that portfolio investment can diversify risk. In his view, the goal of the investment is to maximize return at the same level of risk or minimize risk at the same level of return. Return and risk are like two sides of the same coin and cannot be separated. Markowitz uses the mean of the historical returns to portray the investor's expected return and the variance of the portfolio return to describe the risk. Risk, or the variance of portfolio returns, can be split into two components. The systematic risk can be expressed as the covariance between assets and the uncertainty caused by factors that affect all assets. The non-systematic risk is expressed as the variance of individual asset returns, which is the uncertainty of returns caused by factors of

*Ruipeng.Tan001@umb.edu 
individual assets. Markowitz used mathematical methods to prove that when investors reduce the correlation of stocks in a portfolio, they can reduce the risk of achieving this return by investing in more stocks at a certain level of return. Markowitz's second innovation is to guide investors in identifying the optimal level of diversification in order to determine the best portfolio. Guided by investment objectives and diversification principles, investors can identify optimal portfolios at different risk levels, which Markowitz outlines on a two-dimensional plane with an efficient frontier curve. With the range of options available, investors can choose the portfolio that satisfies them most according to their respective risk preferences. These principles and theories have been widely used in the portfolio management area. This paper also applies the Markowitz portfolio construction to study the changes in the portfolio construction before and after the outbreak of the pandemic to see what kinds of adjustment that has been brought to the market.

\section{METHOD}

In this research paper, the portfolio analysis of six stocks is conducted to construct an efficient portfolio under the Markowitz theory. The Monte Carlo method is used in the simulation as it is generating samples from the probability distribution. The six stocks are Apple Inc (AAPL), Alibaba Group Holding Ltd (BABA), Facebook, Inc. (F.B.), Microsoft Corporation (MSFT), Tesla Inc (TSLA), and Twitter Inc (TWTR). The study period is from Jan 2018 to Dec 2020. The time period from Jan 2018 to Dec 2019 is set to be the pre-crisis period, and the time period from Jan 2020 to Dec 2020 is set to be the post-crisis period.

\subsection{Data Source}

All the stock price data are public data obtained from Yahoo Finance [5].

\subsection{Data Description and Analysis}

As shown in Figure 1, we can see the close price of the six stocks from 2018 to 2019 in the pre-crisis period. In this period, Microsoft shows strong growth in the past two years. Facebook and Alibaba Group had a more volatile growth from 2018 to 2019. Tesla and Apple have stable growth in this period, while Twitter had a flatter growth trend in this period.

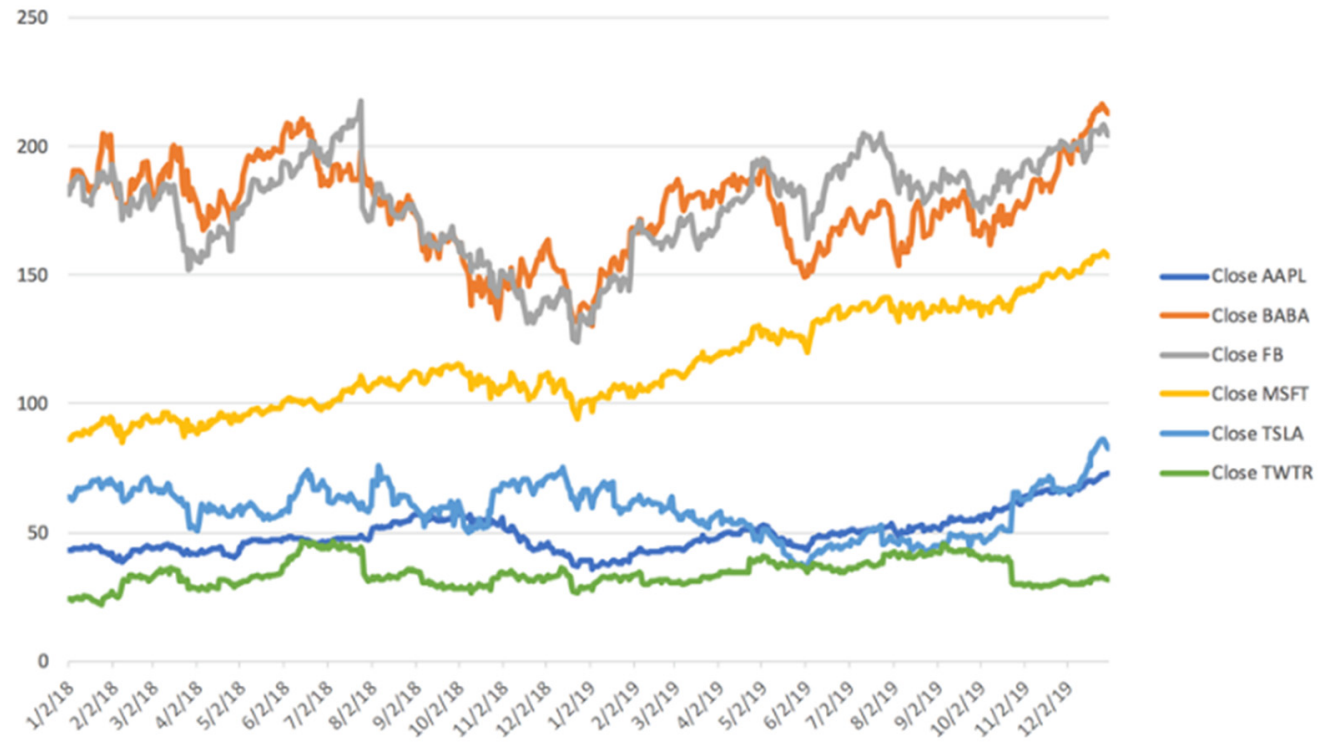

Figure 1. The stock price of six tech stocks from 2018 to 2019

Figure 2 shows the six stocks in 2020. All these six stocks got a hit at the beginning of 2020 when the pandemic started to spread. Since March 2020, the Tesla stocks started to soar to around $\$ 600$ at the end of 2020 from around $\$ 100$ at the beginning of 2020. The Tesla stock soared over six times in 2020. 


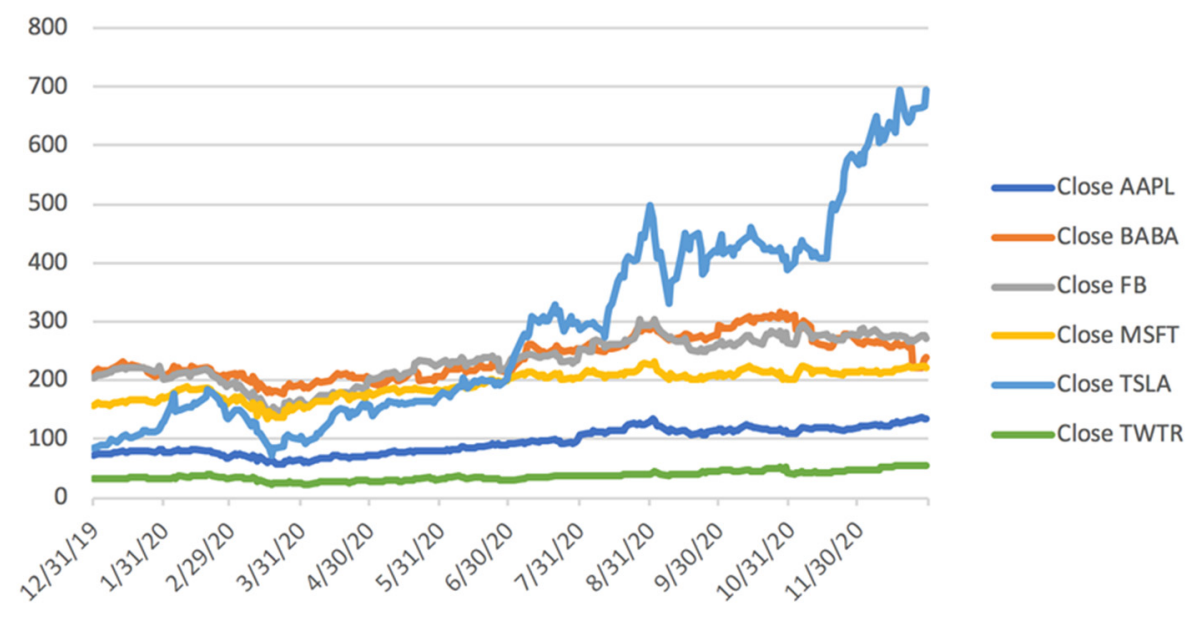

Figure 2. The stock price of six tech stocks in 2020

Below is a table on the descriptive data of Apple. Alibaba and Facebook stocks returns. The average daily stock return for Apple was $0.12 \%$ before the pandemic outbreak, and this raised to $0.28 \%$ in the post-crisis period. The variance of the Apple stock returns also increased from the pre-crisis period to the post-crisis period. Perhaps the biggest concern for investors in technology companies, especially technology hardware companies, is the impact of a coronavirus pandemic on global supply chains and shipments. With Apple's supply chain spread across multiple countries, its shareholders are not immune to concerns about the outbreak. In fact, Apple has long warned that production challenges and slowing demand in China will cause the company to fall behind its earnings guidance for its second fiscal quarter. Fortunately, Apple is much more than a technology hardware company; it's a service business. The business in question earns revenue from services such as e-sales and subscriptions from the App Store, advertising, iCloud, AppleCare, and licensing, and has become the second-largest segment after iPhone. In the first quarter of fiscal 2020, Apple's services revenue rose $17 \%$ year-over-year, driven by double-digit growth recorded across all geographic segments, according to Forbes [6]. The coronavirus outbreak has caused more people to stay home, spurring Apple's services revenue in the period.

As for Alibaba Group, the average daily stock return was $0.05 \%$ before the pandemic outbreak, and this raised to $0.08 \%$ in the post-crisis period. The variance of the Alibaba stock returns increased from $2.08 \%$ in the precrisis period to $2.59 \%$ in the post-crisis period. This was due to the interruption of the IPO of the Ant Group, one of the largest subsidiary companies of Alibaba. This abrupt stop of the IPO was announced due to the statement from Chinese officials that the Ant Group did not meet the Chinese regulatory and requirements regarding its operation as a Fintech company [7]. If this Ant Group IPO were not into a sudden cutoff, the year of 2020 could be a huge mark for Alibaba to show a strong group in this tough year. Alibaba's business was also thriving under the pandemic outbreak as the demand for online shopping and delivery went up during the lockdown period.
Table1. Descriptive data on Apple, Alibaba Group, and Facebook before and after the pandemic

\begin{tabular}{|c|c|c|c|c|c|c|}
\hline & $A A P L$ & & BABA & & FB & \\
\hline & before & after & before & after & before & after \\
\hline Mean & 0.001 & 0.003 & 0.001 & 0.001 & 0.000 & 0.002 \\
\hline $\begin{array}{l}\text { Standard } \\
\text { Error }\end{array}$ & 0.001 & 0.002 & 0.001 & 0.002 & 0.001 & 0.002 \\
\hline Median & 0.002 & 0.002 & 0.002 & 0.001 & 0.001 & 0.002 \\
\hline $\begin{array}{l}\text { Standard } \\
\text { Deviation }\end{array}$ & 0.017 & 0.029 & 0.021 & 0.026 & 0.021 & 0.029 \\
\hline $\begin{array}{l}\text { Sample } \\
\text { Variance }\end{array}$ & 0.000 & 0.001 & 0.000 & 0.001 & 0.000 & 0.001 \\
\hline Kurtosis & 3.907 & 3.703 & 0.358 & 3.603 & 15.535 & 3.508 \\
\hline Skewness & -0.425 & -0.061 & -0.075 & -0.598 & -1.295 & -0.197 \\
\hline Range & 0.170 & 0.248 & 0.136 & 0.223 & 0.298 & 0.245 \\
\hline
\end{tabular}

As for Facebook, the average daily stock return was $0.04 \%$ before the pandemic outbreak, and this raised to $0.15 \%$ in the post-crisis period. The variance of the Facebook stock returns increased from $0.04 \%$ in the precrisis period to $0.08 \%$ in the post-crisis period. Facebook reported an $18 \%$ increase in first-quarter revenue, indicating strong demand for advertising before the Covid-19 pandemic hit marketing budgets [8]. The company's first-quarter sales were $\$ 17.7$ billion, according to data compiled by Bloomberg, and the results include just a few weeks after the coronavirus blockade began hitting the economy in March [9]. The company's operations have seen signs of stabilization after an initial steep drop in advertising revenue in March. The company's services are getting more and more use as millions of people hide away, looking for ways to be entertained and stay connected online. The company said the average daily user base for all Facebook apps, including Instagram and WhatsApp, rose to 2.36 billion in March from 2.26 billion in December [10]. The core social 
network at Facebook now has 1.73 billion daily users, compared with 1.66 billion in the last month of 2019 [9]. This spike is likely to have less of an impact on Facebook's business than in previous quarters. Many of the company's most popular features during the pandemic (including voice calling and direct messaging) were not sizable revenue areas for the company. Facebook also received more than half of its sales from small businesses suffering from Covid-19 lock-in and recession. However, some are optimistic that the popularity of the company's messaging products will pay off in the near future, which will provide alternative business for the advertising industry.

As for Microsoft corporation, the average daily stock return was $0.13 \%$ before the pandemic outbreak, and this raised to $0.17 \%$ in the post-crisis period. The variance of the Facebook stock returns increased from $0.02 \%$ in the pre-crisis period to $0.07 \%$ in the post-crisis period. As more and more people work remotely from home, the use of its cloud infrastructure services, including Microsoft Teams, Windows Virtual Desktop, and Power B.I., has increased dramatically, with demand in areas with social isolation or social distancing measures. In areas with social isolation or shelter-in-place initiatives, demand for online services jumped. Microsoft is benefiting from high growth in cloud services revenue and a subscription-based transformation of its traditional business. Microsoft Azure has become the cloud service second only to Amazon AWS, and the increased weight of cloud services has given Microsoft more resilience in this epidemic [11]. Microsoft's relationship with competitors such as Apple and Google is also improving, and the Office suite has become one of the most popular apps for iOS/Android. Subscription-based individual products also add to the sustainability of revenue. Businesses won't stop their cloud service needs because of an epidemic, and individuals won't stop using genuine Office because of an epidemic. This simple fact is the source of Microsoft's strong resilience.

Table2. Descriptive data on Microsoft, Tesla, and Twitter before and after the pandemic

\begin{tabular}{lcccccc}
\hline & MFST & & TSLA & \multicolumn{3}{c}{ TWTR } \\
& before & after & before & after & before & after \\
\hline Mean & 0.001 & 0.002 & 0.001 & 0.010 & 0.001 & 0.003 \\
Standard & 0.001 & 0.002 & 0.002 & 0.004 & 0.001 & 0.002 \\
$\begin{array}{l}\text { Error } \\
\text { Median }\end{array}$ & 0.002 & 0.003 & -0.001 & 0.007 & 0.002 & 0.003 \\
$\begin{array}{l}\text { Standard } \\
\text { Deviation }\end{array}$ & 0.015 & 0.028 & 0.034 & 0.056 & 0.032 & 0.039 \\
& & & & & & \\
$\begin{array}{l}\text { Sample } \\
\text { Variance }\end{array}$ & 0.000 & 0.001 & 0.001 & 0.003 & 0.001 & 0.002 \\
& & & & & & \\
Kurtosis & 2.719 & 6.398 & 5.014 & 2.267 & 10.236 & 6.297 \\
Skewness & -0.010 & -0.070 & 0.492 & -0.181 & -0.682 & -0.808 \\
Range & 0.130 & 0.290 & 0.316 & 0.410 & 0.365 & 0.361 \\
\hline
\end{tabular}

For Tesla, the average daily stock return was $0.10 \%$ before the pandemic outbreak, and this raised to $1.00 \%$ in the post-crisis period. The variance of the Tesla stock returns increased from $0.11 \%$ in the pre-crisis period to $0.31 \%$ in the post-crisis period. Tesla, founded by Musk, saw its share price nine-fold from $\$ 88.60$ at the beginning of 2020 to a peak of $\$ 705.67$ at the end of the year, which has seen the company's market capitalization grow from $\$ 76$ billion to $\$ 669$ billion. This performance has left no shadow of the epidemic that shut down several of their production lines early last year. The demand and trend for a new energy company and the investment have been soaring in the year 2020, and Tesla is for sure one of the largest winners in this game.

For Twitter, the average daily stock return was $0.10 \%$ before the pandemic outbreak, and this raised to $0.29 \%$ in the post-crisis period. The variance of the Twitter stock returns increased from $0.10 \%$ in the pre-crisis period to $0.15 \%$ in the post-crisis period.

\subsection{The Monte Carlo Simulation}

Monte Carlo simulation is a method that iteratively generates time series by setting up a stochastic process, calculates parameter estimates and statistics, and then studies their distribution characteristics. The Monte Carlo Method is also known as a computerized stochastic simulation method, which is a computational method based on random numbers and is a generic term for a class of stochastic methods [12]. The characteristic of this type of method is that the approximate result can be calculated on random sampling, and as the sampling increases, the probability that the result is the correct result gradually increases. Until the true result is obtained by abandoning random sampling and using a deterministic method like full sampling, it is impossible to know whether the result obtained so far is the actual result. For many problems, it is often the simplest method of computation and sometimes the only feasible one. Monte Carlo methods are widely used in the fields of financial engineering, macroeconomics, and computational physics.

\section{RESULT AND DISCUSSION}

This paper performs data analysis on these six stock returns using over 1000 Monte Carlo simulations to perform the portfolio analysis and find out the optimal portfolio construction before and after the pandemic outbreak. Below is the efficient frontier before the pandemic outbreak using stock data from 2018 to 2019. The portfolio construction is listed below.

Table3. Portfolio Construction of six stock before the pandemic outbreak

\begin{tabular}{ccccccc}
\hline $\begin{array}{c}\text { Before the } \\
\text { pandemic }\end{array}$ & AAPL & $\begin{array}{c}\text { BAB } \\
\text { A }\end{array}$ & FB & MSFT & TSLA & $\begin{array}{c}\text { TWT } \\
\text { R }\end{array}$ \\
\hline $\begin{array}{c}\text { Minimum } \\
\text { Volatility } \\
\text { portfolio }\end{array}$ & $32.09 \%$ & $1.54 \%$ & $0.07 \%$ & $59.42 \%$ & $0.97 \%$ & $5.91 \%$ \\
\hline $\begin{array}{c}\text { Maximum } \\
\text { Sharpe } \\
\text { Ratio } \\
\text { portfolio }\end{array}$ & $27.08 \%$ & $1.87 \%$ & $14.09 \%$ & $48.64 \%$ & $7.46 \%$ & $0.86 \%$ \\
\hline
\end{tabular}




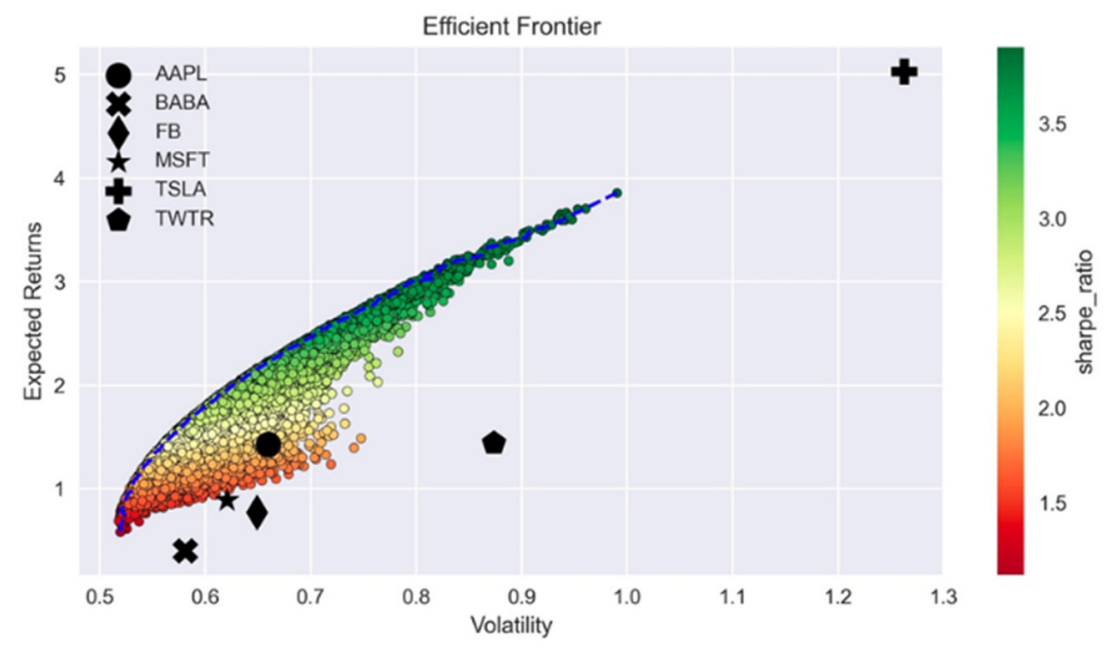

Figure 3. Efficient frontier graph on the portfolio using Matlab before the pandemic outbreak

Looking at the portfolio construction before and after the pandemic outbreak, we can see that the weights in Tesla got greatly increased while the weight in Microsoft stock decreased from around $50 \%$ to a much lower level.
Table4. Portfolio Construction of six stock after the pandemic outbreak

\begin{tabular}{ccccccc}
\hline $\begin{array}{c}\text { After the } \\
\text { pandemic }\end{array}$ & AAPL & BABA & FB & MSFT & TSLA & TWTR \\
\hline $\begin{array}{c}\text { Minimum } \\
\text { Volatility } \\
\text { portfolio }\end{array}$ & $15.36 \%$ & $5.17 \%$ & $1.49 \% \%$ & $0.92 \%$ & $63.56 \%$ & $13.49 \%$ \\
\hline $\begin{array}{c}\text { Maximu } \\
\text { m Sharpe } \\
\text { Ratio } \\
\text { portfolio }\end{array}$ & $5.01 \%$ & $48.14 \%$ & $23.57 \%$ & $19.89 \%$ & $0.43 \%$ & $2.96 \%$ \\
\hline
\end{tabular}

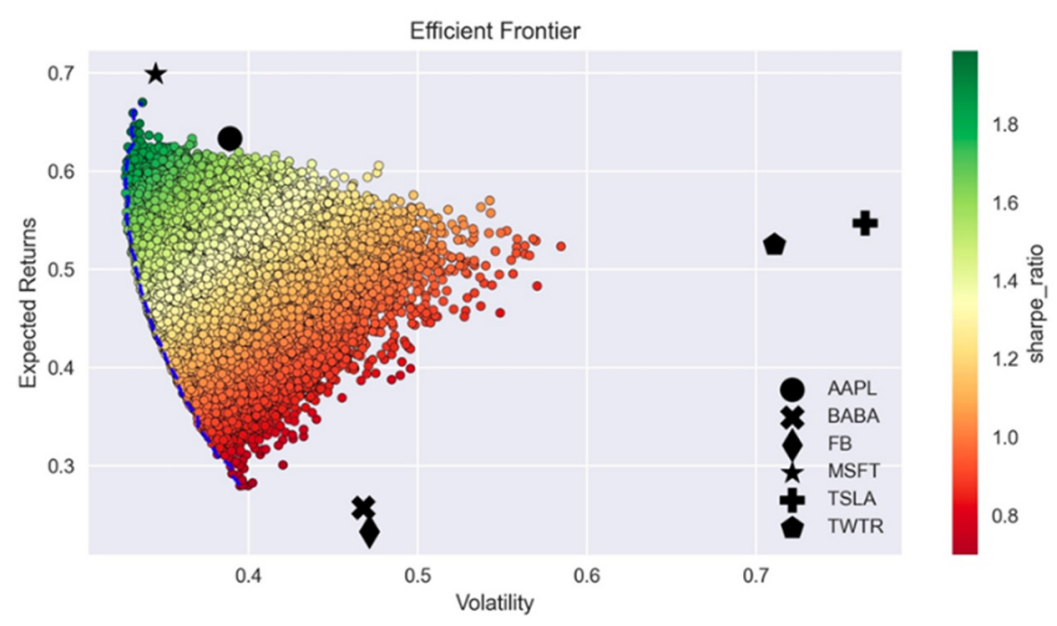

Figure 4. Efficient frontier graph on the portfolio using Matlab after the pandemic outbreak

From the comparison between these two portfolio constructions, we can see that COVID-19 has shifted the investment focus in the high-tech industry. New energy and the electric vehicle worth great attention and are seen as the next future trend. While for tech companies whose core business is traditional hardware like Microsoft, the portfolio weights are expected to decrease.

\section{RECOMMENDATION AND CONCLUSION}

Since February 2020, global stock markets have plunged due to the epidemic and have rebounded to varying degrees. In this round of rebounds, the technology giants such as Microsoft, Apple, Amazon, and Google have performed the best. There are three main reasons why these companies have managed to rise against the trend and even hit new all-time highs: good financial condition, positive market expectations, and the Federal Reserve's quantitative easing policy. A good financial position is a major reason. With Apple's cash reserves exceeding \$200 billion and Microsoft's cash reserves exceeding $\$ 130$ billion, there was no pressure to survive the epidemic. Second, while the epidemic has also had a significant negative impact on large tech stocks, they will have far more stamina to persevere in difficult times, and can even use difficult times to acquire others' high-quality assets and expand their reach. This is because these companies 
have deep moats, strong innovation capabilities, and more cash reserves. In order to cope with the downward pressure of the economy, the Federal Reserve has offered zero interest rate + unlimited quantitative easing policy. So much liquidity will surely find a suitable place to go, which has provided the impetus for the recent rally of U.S. stocks. For the tech giants, there is actually a divergence. If a company's business is mainly subscription-based paid, enterprise cloud services for individual users, the trend is stronger during the epidemic for Amazon, Microsoft. If it relies more on advertising placed by merchants, the performance is relatively weaker such as Facebook and Google.

Certain regions and asset classes did quite well in the face of the turmoil caused by the epidemic and the accompanying embargo, especially large-cap technology and upper retail stocks, thanks to the "work-from-home" trend. One of the big positive news is that the vaccine trial is expected to be successful by the end of 2020. However, it is unclear how long it will take to launch the vaccine and how many people will be willing to receive it. Until there is widespread vaccination, it is feared that many regions will continue to suffer from subsequent outbreaks. As a result, the global growth outlook will remain uncertain, and private sector spending (both private consumption and investment) is likely to be depressed until effective vaccines and treatments are universally adopted. Equity markets may also suffer if cyclical economic data lose momentum, and the dip will be particularly severe if markets find asset prices disconnected from economic fundamentals.

While investors may be optimistic that a potent new crown vaccine will be available in 2021 , the path to economic recovery remains uncertain. We, therefore, need a broader range of investment vehicles that are not limited to regions, sectors, and strategies that have performed well recently. While the severe recession is over, a return to the pre-epidemic growth trajectory is still several years away. While some countries are facing a new wave of infections and city closures, the global economy has recovered from the deep recession triggered by the epidemic. Beyond the sectors that thrived during the epidemic crisis, investors are hoping to find new sources of potential returns to benefit from the recovery process going forward. Much of this depends on the successful application of effective vaccines and drug therapies. New vaccines appear to offer hope, but going forward, investors will need to keep a close eye on important macroeconomic data points for signs of renewed growth momentum. European and Asian equities, value sectors, and corporate bonds may hold investment potential if the outbreak is contained. For institutional investors, the private equity market has investment potential, especially as infrastructure investment is expected to increase (thanks in part to stimulus measures aimed at boosting economic activity). There will be an increasing number of investment opportunities to support a sustainable and resilient economic recovery after the epidemic, such as investments to address climate change and other important issues.

\section{APPENDIX}

\subsection{Python Code and Result for Portfolio Construction Testing}

Results on data from 2018.01.01 to 2019.12.31

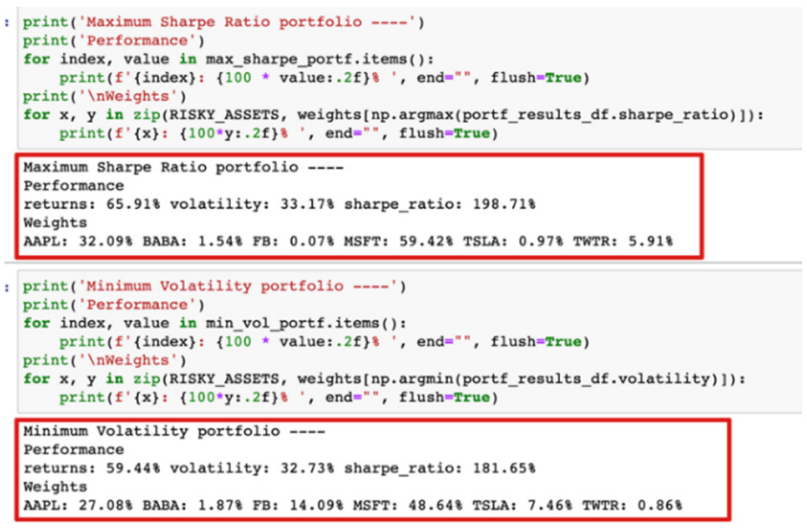

Results on data from 2020.01.01 2020.12.31

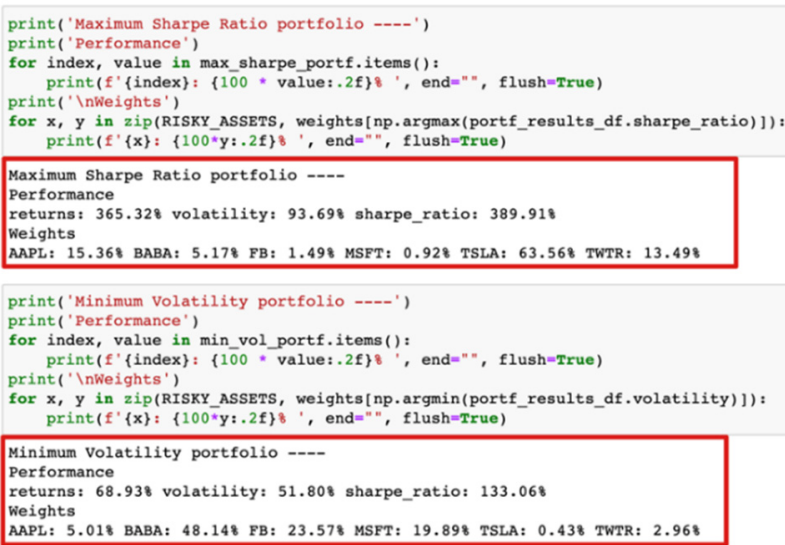

\subsection{Descriptive Data on the Sample Stocks}

\begin{tabular}{|c|c|c|c|c|c|c|c|c|c|c|c|c|}
\hline & AAPL & & BABA & & $\mathrm{FB}$ & & MFST & & TSLA & & TWTR & \\
\hline & before & after & before & after & before & after & before & after & before & ofter & before & after \\
\hline Mean & 0.001202 & 002815 & 0005129 & 0.00080269 & 00046389 & 0.00153605 & 0.00132939 & 0.00173562 & 0.00109012 & 0.01002439 & 0.00104635 & 0.00287291 \\
\hline Standard Error & 0.000776 & 0.001855 & 0.00093279 & 0.00163385 & 0.00093988 & 0.00182493 & 0.00068903 & 0.00174519 & 0.00152386 & 0.00355074 & 0.00141695 & 0.00245649 \\
\hline Median & 0.001570 & 0.002005 & 0.0015825 & 0.0011539 & 0.00095144 & 0.00217445 & 0.00182775 & 0.00250921 & -0.0006121 & 0.00747789 & 0.00207038 & 0.00329758 \\
\hline Standard Deviation & 0.017371 & 0.029443 & 0.02087877 & 0.02593656 & 0.0210373 & 0.02896979 & 0.01542263 & 0.02770404 & 0.03410871 & 0.05636622 & 0.03171565 & 0.03899553 \\
\hline Sample Variance & 0.000302 & 0.000867 & 0.00043592 & 0.0006727 & 0.00044257 & 0.00083925 & 0.00023786 & 0.00076751 & 0.0011634 & 0.00317715 & 0.00100588 & 0.00152065 \\
\hline Kurtos is & 3.907496 & 3.703418 & 0.35784045 & 3.60315324 & 15.5345596 & 350785156 & 2.71892735 & 6.39815566 & 5.01432021 & 2.26686181 & 10.2358411 & 6.29733788 \\
\hline Skewne: & -0.425444 & -0.060569 & -0.0746899 & -0.598448 & -1.2945118 & -0.1971455 & -0.009825 & -0.0699314 & 0.49237024 & -0.1808535 & -0.682176 & -0.8084961 \\
\hline Range & 0.170029 & 0.248455 & 0.13648516 & 0.22293174 & 0.29777306 & 0.24487993 & 0.13004355 & 0.28955919 & 0.31570771 & 0.40957689 & 0.36452743 & 0.36148308 \\
\hline Minim & -0.099607 & -0.128647 & -0.066424 & -0.1334218 & -0.1896092 & -0.14253 & -0.0543381 & -0.1473903 & -0.1390154 & -0.2106283 & -0.2080866 & -0.2111387 \\
\hline Maximum & 0.070422 & 0.119808 & 0.07006121 & 0.08950995 & 0.10816384 & 0.10234995 & 0.07570542 & 0.14216888 & 0.17669232 & 0.19894863 & 0.15644086 & 0.15034443 \\
\hline Sum & 0.602168 & 0.709274 & 0.25696478 & 0.20227912 & 0.23240843 & 0.38708359 & 0.66602536 & 0.43737714 & 0.54614815 & 2.52614509 & 0.52422177 & 0.72397319 \\
\hline Count & 501 & 252 & 501 & 252 & 501 & 252 & 501 & 252 & 501 & 252 & 501 & 252 \\
\hline Largest (1) & 0.070422 & 0.119808 & 0.07006121 & 0.08950995 & 0.10816384 & 0.10234995 & 0.07570542 & 0.14216888 & 0.17669232 & 0.19894863 & 0.15644086 & 0.15034443 \\
\hline Smalle & & -0.128 & & -0.1334218 & & & 81 & -0. & -0. & 06283 & 80866 & 1387 \\
\hline Confidence Level $(95.096)$ & 0.001525 & 0.003653 & 0.00183268 & 0.0032178 & 0.0018466 & 0.00359412 & 0.00135375 & 0.00343708 & 0.00299397 & 0.00699304 & 0.00278391 & 0.00483795 \\
\hline
\end{tabular}




\section{REFERENCES}

1. Markowitz, H. M. (1991). Foundations of portfolio theory. The journal of finance, 46(2), 469-477.

2. CDC. (2021). COVID Data Tracker. Centers for Disease Control and Prevention. URL: https:/covid.cdc.gov/covid-datatracker/\#datatracker-home

3. Choi, D. (2020). Fed slashes main interest rate to near zero in historic move designed to cushion economic blow of coronavirus pandemic. The Business Insider. URL: https://www.businessinsider.com/fed-interestrate-cut-zero-bond-holdings-coronavirus-pandemiceconomy-2020-

3\#: :text $=$ The $\% 20$ Federal $\% 20$ Reserve $\% 20$ on $\% 20 \mathrm{~S}$ unday $\% 20$ slashed $\% 20$ its $\% 20$ benchmark $\% 20$ interest $\% 20$ rate,bond $\% 20$ holdings $\% 20$ by $\% 20 \% 24700 \% 20$ b illion.

4. Sharpe, W. F. (1964). Capital asset prices: A theory of market equilibrium under conditions of risk. The journal of finance, 19(3), 425-442.

5. Yahoo Finance website. (2021). Stock return data/ URL:Data source website: https://finance.yahoo.com

6. Forbes. (2020). Apple Stock Is Up 50\% This Year. What's Going On? URL:

https://www.forbes.com/sites/greatspeculations/2020 /08/20/apple-stock-is-up-50-this-year-whats-goingon/?sh=20a273226505
7. Gurdus, Lizzy. (2020). Ant Group's IPO won't happen for at least six months after regulatory hurdles, China ETF issuer says. The CNBC. URL: https://www.cnbc.com/2020/11/14/why-the-antgroup-ipo-wont-happen-for-at-least-six-months.html

8. Rodriguez, S. (2020). Facebook soars after reporting 'stability' in ad revenue after fall in March. The CNBC Website. URL:

https://www.cnbc.com/2020/04/29/facebook-fbearnings-q1-2020.html

9. Wagner. K. (2020). Facebook Surges After Revenue Holds Up in Midst of Pandemic. The Bloomberg Technology. URL:

https:/www.bloomberg.com/news/articles/2020-0429/facebook-says-revenue-held-up-in-midst-ofpandemic-shares-surge

10. Dreller, J. (2020). Facebook signals online advertising to take a big hit. The digital commerce 360. URL:

https://www.digitalcommerce360.com/2020/04/30/fa cebook-signals-online-advertising-to-take-a-big-hit/

11. Digna, L. (2021). Top cloud providers in 2021: AWS, Microsoft Azure, and Google Cloud, hybrid, SaaS players. URL: https://www.zdnet.com/article/thetop-cloud-providers-of-2021-aws-microsoft-azuregoogle-cloud-hybrid-saas/

12. Palisade. (2020). What is Monte Carlo Simulation? URL:

https://www.palisade.com/risk/monte_carlo_simulati on.asp 